\title{
Prosocial Rule Breaking (PSRB): Going Beyond The Limits
}

\author{
${ }^{1-3}$ Assistant Professor, Shri Ramdeobaba College of Engineering and Management, Nagpur \\ Email: bhadadepr1@rknec.edu,saorn@rknec.edu, chandaksj3@rknec.edu
}

\author{
Received: $20^{\text {th }}$ September 2018, Accepted: $11^{\text {th }}$ October 2018, Published: $31^{\text {st }}$ October 2018
}

\begin{abstract}
The paper makes an attempt to throw light on the concept of prosocial rule breaking behavior. This study will identify the instances of PSRB at the workplace and the reasons of demonstration of prosocial rule breaking by the employees. This is an exploratory study purely based on secondary data published in various research papers, reports and articles.

Deviance from work or not following the rules and regulations has always been considered as against the organization. The deviance behavior may be constructive or destructive. However, there are certain behaviors which are now termed as positive when it comes to breaking rules for the benefit of any stakeholder. Positive deviance from any rule of the company is definitely breaking of rule or code of conduct. But, what if the rule breaking is for the benefit of the employee or any client? Prosocial rule breaking is practiced by many employees for the right reasons. PSRB is also called as a constructive deviance which is in the greater interest of the organization. It is often done to retain the clients and customers and provide them satisfaction.

The perception for the same action under PSRB may sometimes be considered as positive or negative deviance depending upon the impact of the action; for instance, whistleblowing. Studies have established a certain relationship of PSRB with job autonomy, coworker behavior and risk taking tendency.
\end{abstract}

\section{Keywords}

Constructive Deviance, Coworker, Customer, PSRB

\section{Introduction}

The concept of prosocial behavior is first applied by A. P. Brief and S. J. Motowidlo to an organizational context. The root of origination of pro-social behavior is in behavior science literature. The individual can go above and beyond its responsibilities assigned to them in an effort to aid others [1]. If any employee breaks a rule, he / she would probably land up getting a warning or even a termination for noncompliance with company rules and policies. We often feel that the disgruntled employees who are critics of the system may act as rebellious and think of breaking the rules. The breaking of formal rules is generally viewed as unusual behavior displayed by angry or selfinterested employees, or by employees who do not identify with the organization or its goals. In contrast this paper highlights that the rule breaking often represents positively intended employee initiative, referred to here as prosocial rule breaking. Pro-social rule breaking is defined as any instance where an employee intentionally violates a formal organizational policy, regulation, or prohibition with the primary intention of promoting the welfare of the organization or one of its stakeholders [2]. But, when we talk about the concept of prosocial rule breaking (PSRB), certain companies may also give reward to the employees for breaking a rule.

On many occasions, we often experience help coming from some employees which were never expected. This is truly an action on part of the employee where he / she is going beyond the norms of the organization to help the customer. PSRB is a behavior where the employee would go beyond the role to provide a service to the customer or any other stakeholder with an objective to help them or to give a solution which ideally they are not allowed. Nursing staff may sometimes allow the patients to eat homemade food which is not allowed in the hospital for the satisfaction of the patient or his / her family. There are certain restrictions in the hotel industry wherein they are also very specific about the ingredients of a particular recipe and how it should be served. But, in order to provide customer delight, the chefs may go ahead with satisfying the customer by bending a rule of their hotel.

Imagine the following scenario, a customer issued a cheque. While clearing cheque the bank employee came to know that the customer does not have sufficient balance in his/her account hence, a cheque cannot be cleared. The bank employee knew that if the cheque gets bounced the customer will be fined for the bounced cheque and credit rating of a customer will be reduced. The bank employee informed the customer and gave him time by delaying the clearing of the cheque so that the customer can make necessary arrangement for the required balance in an account. The bank employee willingly went beyond his/her limit to break organizational rules and risk disciplinary action to better service a customer. The behavior showed by a bank employee is constructive deviance in the interest of stakeholder. 
PSRB is not only for the stakeholders, but the hidden objective always remains in the interest of the company. Is ethics involved with PSRB? The answer is obviously yes and that is the reason that a lot of studies has been done to check the relationship between ethics and PSRB.

\section{Materials and Methods}

The study is qualitative and exploratory in nature which draws theoretical and conceptual framework of prosocial rule breaking behavior. This study is an attempt to identify the factors affecting prosocial rule breaking behavior in employees working at various organizations. The rule breaking can be in the interest of the organization or in the interest of self. In this study, the authors have tried to focus on the prosocial rule breaking behavior.

This paper brings about the concept of prosocial rule breaking with the help of a literature review in the form of research papers and various articles published by various HR practitioners. The concept of PSRB is an emerging concept in the field of organization behavior. There are many researchers who have coined definitions and meaning to the concept. This paper is an attempt to collate the entire pool of study done in the field of PSRB in the past and organize them to provide more meaningful insights for future research.

There are various sectors and instances wherein PSRB can be actually practiced by the employees and somewhere it is not possible like in specific cases of confidentiality and fragile information.

\section{Results and Discussion}

Morrison (2006) introduced the construct of PSRB. Morrison notes that, rule breaking behavior can be influenced negatively or positively intention. While rule breaking is generally conceptualized as a negatively deviant behavior by angry or self-interested employees or employees may also break rules for positive, prosocial reasons. Prosocial reasons may be promoting the welfare of an organization or one of its stakeholders. In order to perform the job in an "effective, responsible, and responsive manner" the employees might engage in rule breaking and they feel it is necessary to break organizational rules in order to do so. Morrison defined PSRB as "any instance where an employee intentionally violates a formal organizational policy, regulation, or prohibition with the primary intention of promoting the welfare of the Employee Pro-social Rule Breaking organization or one of its stakeholders". Thus, Morrison viewed rule breaking as stemming not from a desire to harm the organization but from a desire to help.

In her initial study of PSRB, Morrison identified three forms of PSRB: rule breaking to facilitate work performance, rule breaking to help another member of the organization, and rule breaking to provide good customer service. Morrison conducted three studies to shed the light on pro-social rule breaking behavior. The first two studies were qualitative and exploratory in which Morrison focused on providing evidence of the existence of PSRB and the motives that drive such behaviors. The third was experimental based study using scenario to identify contextual and individual variables of an employee engage in pro-social rule breaking. Results from phone interviews with 24 individuals in a broad range of jobs (Study 1) and face-to-face interviews with 79 individuals (Study 2), demonstrated most individuals reported incidents of engaging in PSRB. In Study 3, Morrison sought to provide greater understanding about the antecedents of PSRB. It further supports for the idea that individuals are willing to break a rule in the interest of meeting the deadline or customer request under certain conditions. She examined six factors that might predict PSRB behavior: job meaning, job autonomy, empathy, proactive personality, risk-taking propensity, and coworker rule-breaking behavior. The gender has a significant difference in the likelihood to participate in pro-social rule breaking. The females were less likely to participate in pro-social rule breaking behavior [2] [3].

Morrison found employees' likelihood of engaging in PSRB was influenced by their job meaning, job autonomy, empathy, proactive personality, the behavior of their coworkers, and their propensity for risk-taking.

The prosocial rule breaking behavior is an ethical decision. It requires tradeoffs and ethical assessment [4]. James M. Vardaman et al. presented a conceptual model of ethical climate and PSRB in a workplace which is an extension of Victor and Cullen's (1988) five-dimensional typology of organizational ethical climate. The PSRB is a choice between alternatives which consist of good and bad alternatives. It is not a decision between good or bad. The fivedimensional typology of ethical climate types (Instrumental, Caring, Independence, Rules and Law and Code) are positively and negatively associated with PSRB. Ethical climates when they are positively associated with PSRB then it will enhance the positive linkages between individual factors and PSRB and when they are negatively associated with PSRB it will mitigate positive linkages between individual factors and PSRB [4].

Maureen L. Ambrose, Regina Taylor, Ronald L. Hess Jr., suggested a "deontic" customer-directed PSRB model. According to them the customer-directed PSRB is influenced by the attributes of employee, customer, and situation. These models help us to understand better how an employee respond to the perceived mistreatment of customers as shown in figure 1 given below [5]. The organization culture and climate should be fair and transparent. On the other 
hand if the employee perceives the climate is not fair and positive they may suffer due to it and would feel the same for the customers this results in voluntary helping to the customers by displaying PSRB/

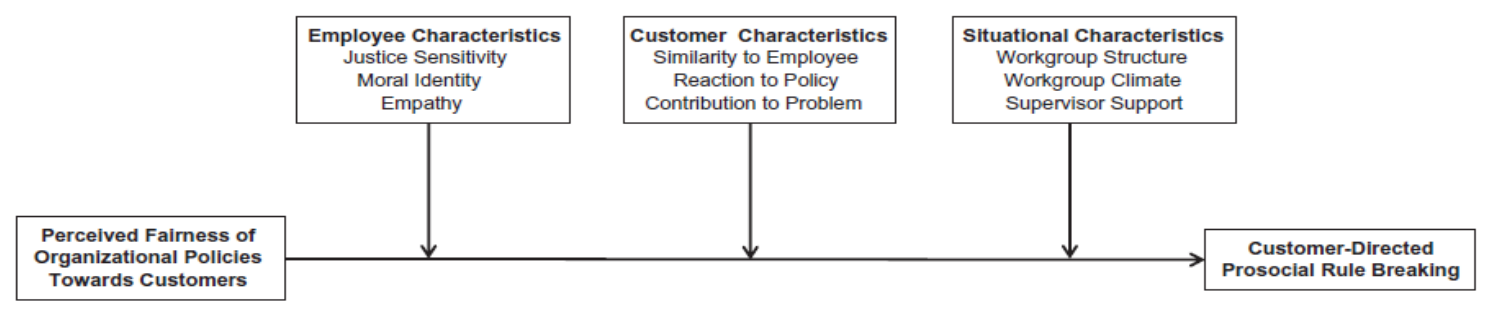

Figure 1: Deontic Customer Directed Prosocial Rule Breaking Model

Youli, Xixi, \& Xi, 2014 conducted a survey on to examine the relationship between transformational leadership, PSRB and Job autonomy. They collected data from 252 employees in different organizations across China. The individuals engaged in transformational leadership roles like inspirational motivation, idealized influence, intellectual stimulation, and individualized consideration behaviors perceived higher levels of prosocial rule breaking behaviors. As per given below figure 2 they have constructed three factor model and found that the job autonomy acts as an intermediary agent to extend the effect of transformational leadership on to PSRB [6].

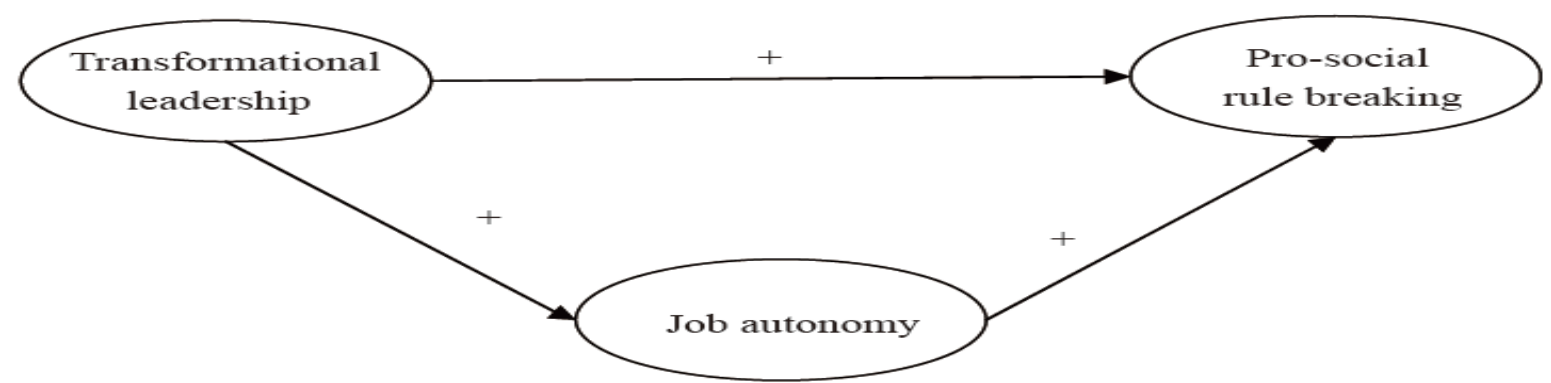

Figure 2: Relationship between Job Autonomy, Transformational Leadership and PSRB

Dahling et.al, 2012 develop a valid measure of PSRB that could be used in a wide variety of organization context i.e. general pro-social rule breaking scale (GPSRBS). The GPSRBS is reliable on all the three studies they have conducted. The exploratory factor analysis is conducted to assess its factor structure. There are five items to measure efficiency reason and co-worker assistance. Four items to measure the customer service. The performance rating and PSRB are negatively related because PSRB is categorized as "pro-social". Thus it is possible that the supervisor may provide a negative performance rating to his/ her co-worker for rule breaking behavior [7].

Catherine R. Curtis et.al surveyed 305 restaurant employees from a nationally branded restaurant chain in the United States. They used service scenario and two scales in the survey to know the perspective of restaurant industry on pro-social rule breaking behavior. This study examines the employee personality (using Big Five Inventory, (BFI): extraversion, agreeableness, conscientiousness, neuroticism, and openness), the degree of autonomy, job meaning, and co-worker influence on an employee's decision to break organizational rules. Agreeableness is the most prominent amongst the personality dimension in hospitality employees followed by Conscientiousness, Extraversion Openness, and then Neuroticism [3] [8] [9]. A restaurant server shows a moderate likelihood of prosocial breaking behavior. The males are more likely to partake as compared females in pro-social rule breaking behavior. In the hospitality industry the restaurant managers may be able to encourage pro-social rule breaking behavior to some extent from their employees. With the help of personality assessment tool the managers can have control over the hiring process. However in the education and training process of employees it must be taken care by the managers that some ways which are beneficial to the customers may be inhibited by other stakeholders [3].

\section{Conclusion}

This study identifies various factors influencing prosocial rule breaking behavior. The factors are job meaning, job autonomy, empathy, proactive personality, the behavior of their coworkers, and their propensity for risk-taking. There are other factors which are customer directed, employee characteristic's (justice sensitivity, moral identity and 
empathy), customer characteristics (reaction to policy, contribution to the problem) and situational characteristics (workgroup climate, structure and support). To measure the PSRB a General PSRB Scale is developed by Dahling et.al, 2012. The males are more likely to partake in pro-social rule breaking behavior. It is also found that the prosocial rule breaking behavior is not always good for the employees. It is possible that the supervisor may provide a negative performance rating to his/ her co-worker for rule breaking behavior. Some gestures which are good for the customers may be dysfunctional to all other parties. In some industry like hospitality the prosocial rule breaking behavior may be used as one of the selection criterion.

\section{References}

1. P. Brief and S. J. Motowidlo, "Prosocial organizational behaviors," Academy of Management Review, p. 710-725., 1986.

2. E. W. Morrison, "Doing the job well: An investigation of pro-social rule breaking.," Journal of Management, vol. 32, no. 1, pp. 5-28, 2006.

3. C. R. Curtis, R. S. Upchurch and D. Dickson, "Restaurant Industry Perspectives on Pro-social Rule Breaking: Intent versus Action," Hospitality Review, vol. 31, no. 1, pp. 1-23, May 2013.

4. J. Vardaman, M. Gondo and D. Allen, "Ethical climate and pro-social rule breaking in the workplace," Human Resource Management Review, vol. 24, no. 1, pp. 108-118, 2014.

5. M. L. Ambrose, R. Taylor and R. L. H. Jr, "Can I Help You? Employee Prosocial Rule Breaking as a Response to Organizational Mistreatment of Customers," Mistreatment in Organizations, pp. 1-31, 2015.

6. H. Youli, L. Xixi and W. Xi, "The Effects of Transformational Leadership on Employee's Pro-social Rule," Canadian Social Science, pp. 128-134, 2014.

7. J. J. Dahling, S. L. M. D. M. Chau and G. J. B., "Breaking Rules for the right reasons?: An investigation of pro-social rule breaking," Journal of Organizational Behavior, pp. 21-42, 2012.

8. K. H.J., K. Shin and W. Umbreit, "Hotel job burnout: The role of personality characteristics," International Journal of Hospitality Management, vol. 26, no. 2, pp. 421-434, 2007.

9. K. W., K. Shin. and N. Swanger, "Burnout and engagement: A comparative analysis using the Big Five personality dimensions.," nternational, vol. 28, no. 1, pp. 96-104, 2009.

10. B. Victor and B. J. \& Cullen, "The organizational bases of ethical work climates.," Administrative Science Quarterly, vol. 33, no. 1, p. 101-125, 1988. 